\title{
Robotic mitral valve operations by experienced surgeons are cost-neutral and durable at 1 year
}

\author{
Garrett Coyan, MD, ${ }^{a}$ Lawrence M. Wei, MD, ${ }^{b}$ Andrew Althouse, PhD, ${ }^{a}$ Harold G. Roberts, MD, ${ }^{b}$ \\ Drew Schauble, MBA, ${ }^{\mathrm{c}}$ Takashi Murashita, MD, ${ }^{\mathrm{b}}$ Chris C. Cook, MD, ${ }^{\mathrm{b}}$ J. Scott Rankin, MD, ${ }^{\mathrm{b}}$ and \\ Vinay Badhwar, $\mathrm{MD}^{\mathrm{b}}$
}

\section{ABSTRACT}

Background: Robotic mitral valve surgery has potential advantages in patient satisfaction and 30-day outcome. Cost concerns and repair durability limit wider adoption of robotic technology. This study examined detailed cost differences between robotic and sternotomy techniques in relation to outcomes and durability following robotic mitral program initiation.

Methods: Between April 2013 and October 2015, 30-day and 1-year outcomes of 328 consecutive patients undergoing robotic or sternotomy mitral valve repair or replacement by experienced surgeons were examined. Multivariable logistic regression informed propensity matching to derive a cohort of 182 patients. Echocardiographic follow-up was completed at 1 year in all robotic patients. Detailed activity-based cost accounting was applied to include direct, semidirect, and indirect costs with special respect to robotic depreciation, maintenance, and supplies. A quantitative analysis of all hospital costs was applied directly to each patient encounter for comparative financial analyses.

Results: Mean predicted risk of mortality was similar in both the robotic $(\mathrm{n}=91)$ and sternotomy $(\mathrm{n}=91)$ groups $(0.9 \%$ vs $0.8 \% ; P>.431)$. The total costs of robotic mitral operations were similar to those of sternotomy $(\$ 27,662$ vs $\$ 28,241$; $P=.273$ ). Early direct costs were higher in the robotic group. There was a marked increase in late indirect cost with the sternotomy cohort related to increased length of stay, transfusion requirements, and readmission rates. Robotic repair technique was associated with no echocardiographic recurrence greater than trace to only mild regurgitation at 1 year.

Conclusions: Experienced mitral surgeons can initiate a robotic program in a cost-neutral manner that maintains clinical outcome integrity as well as repair durability. (J Thorac Cardiovasc Surg 2018;156:1040-7)

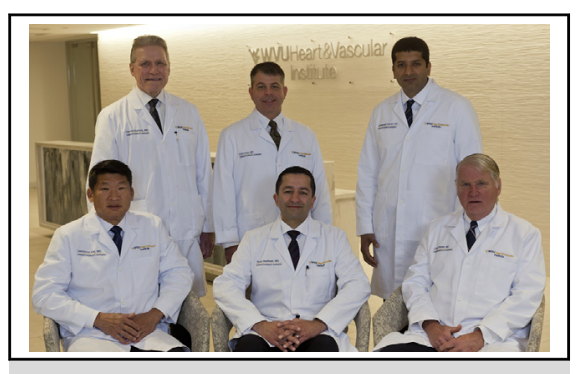

Division of Cardiac Surgery, West Virginia University.

\section{Central Message}

In a propensity-matched activity-based cost analysis, robotic mitral valve repair was durable at 1-year follow-up, and the operation was cost-neutral to sternotomy.

\section{Perspective}

Perceptions of increased cost and unknown durability limit adoption of robotic mitral valve surgery. Applying precise activity-based costing and 1-year echocardiographic followup, robotic technique was cost-neutral to sternotomy and robotic repairs were durable. These findings may assuage initial institutional resistance when experienced surgeons seek to embark on a robotic platform.

See Editorial Commentary page 1048.

See Editorial page 1038 .
Robotic mitral valve repair or replacement (RMVR) has become an acceptable alternative to conventional sternotomy mitral valve repair or replacement (SMVR). ${ }^{1,2}$ RMVR may have similar or decreased morbidity and mortality

From the ${ }^{\mathrm{a}}$ Department of Cardiothoracic Surgery, and ${ }^{\mathrm{c}}$ Financial Services Division, University of Pittsburgh Medical Center, Pittsburgh, Pa; and ${ }^{\mathrm{b}}$ Department of Cardiovascular and Thoracic Surgery, West Virginia University, Morgantown, WVa.

Received for publication Sept 7, 2017; revisions received Feb 12, 2018; accepted for publication March 2, 2018; available ahead of print May 1, 2018.

Address for reprints: Vinay Badhwar, MD, Department of Cardiovascular and Thoracic Surgery, 1 Medical Center Drive, Morgantown, WV 26506 (E-mail: vinay.badhwar@wvumedicine.org).

$0022-5223 / \$ 36.00$

Copyright (c) 2018 by The American Association for Thoracic Surgery

https://doi.org/10.1016/j.jtcvs.2018.03.147 compared with SMVR with comparable short-term valve function. $^{3,4}$ Robotic technique between institutions is becoming more reproducible, producing similar clinical outcomes at all levels of complexity. ${ }^{4-6}$ Successful RMVR may confer reductions in blood transfusions, duration of mechanical ventilation, and hospital length of stay (LOS),

- Scanning this $\mathrm{QR}$ code will take you to a supplemental video for the article. 


$$
\begin{aligned}
& \text { Abbreviations and Acronyms } \\
& \mathrm{ABC}=\text { activity-based costing } \\
& \text { ICU = intensive care unit } \\
& \text { LOS = length of stay } \\
& \text { MR = mitral regurgitation } \\
& \text { PROM = predicted rate of mortality } \\
& \text { PROMM }=\text { predicted rate of mortality and } \\
& \text { morbidity } \\
& \text { RMVR = robotic mitral valve repair or } \\
& \text { replacement } \\
& \text { SMVR = sternotomy mitral valve repair or } \\
& \text { replacement } \\
& \text { STS = Society of Thoracic Surgeons }
\end{aligned}
$$

which may reduce healthcare costs. $^{2,7-9}$ However, 2 important knowledge gaps need to be addressed before wider acceptance of RMVR can occur: unknown repair durability compared with conventional sternotomy and the perception of increased cost, especially when accounting for robotic system acquisition and maintenance..$^{10-14}$

Several techniques have been used to estimate health care costs in cardiac surgery. The majority use hospital charges and relate these to historical institutional costs or costs from the Centers for Medicare and Medicaid Services, and few account for capital equipment costs. ${ }^{15-17}$ Estimates based on charges or work relative value units do not reflect actual hospital costs, often necessitating assumptions, particular when accounting for actual fixed and variable costs. ${ }^{18,19}$ Activity-based costing ( $\mathrm{ABC}$ ) identifies activities at the individual patient level and may more accurately reflect costs attributable to a specific patient encounter to provide a comprehensive assessment of total cost per healthcare event. ${ }^{18-20}$ Direct, semidirect, and indirect costs are accounted for by ABC-specific cost drivers, limiting assumptions or estimates. Although there has been significant maturation in the use of robotic technology, ${ }^{21}$ only limited data are available on the durability of robotic mitral repair and the true patient-level cost differences between RMVR and SMVR. ${ }^{10}$

In this study, we assessed the differences in 1-year outcomes between matched groups of patients undergoing RMVR and those undergoing SMVR following the commencement of a robotic program by surgeons experienced in open mitral operations. The durability of robotic mitral repair was assessed by echocardiography before dismissal or within 30 days and at 1 year after surgery, and total cost was evaluated using $\mathrm{ABC}$ inclusive of robotic capital, instrumentation, and maintenance.

\section{METHODS}

\section{Patient Population}

During the robotic mitral program from April 1, 2013, through October 31,2015 , patients undergoing isolated mitral valve replacement or mitral valve repair were examined. Patients undergoing sternotomy or robotic concomitant tricuspid valve repair, closure of an atrial septal defect, or surgical ablation procedures were included. ${ }^{21}$ Patients with severe aortoiliac occlusive disease, undergoing any other concomitant procedure or reoperation, or requiring emergent or salvage surgery were excluded. As part of an institutional cardiac surgery quality initiative starting in early 2012, all patients were subject to the same preestablished pathways and standardized order sets regarding blood conservation, extubation, intensive care unit (ICU) transfer, and discharge. Baseline demographic, clinical, perioperative and financial data were compiled for all patients.

\section{Surgical Technique}

All operations in both the RMVR and SMVR groups were performed by surgeons with $>10$ years of experience performing mitral valve repair with a minimum of 25 cases annually. The Da Vinci Robotic System (Intuitive Surgical, Sunnyvale, Calif) was used for all RMVR operations. The RMVR technique was standardized in all cases to include a $4-\mathrm{cm}$ right lateral mini-thoracotomy, peripheral cannulation via the femoral artery, and bicaval drainage via the right femoral vein and right internal jugular vein. A transthoracic minimally invasive cross-clamp was used in all RMVR cases. Patients in the RMVR group were not preselected or triaged based on their mitral pathology. All cases involved identical blood cardioplegia regardless of approach.

\section{Financial Data}

Financial data were obtained from specified cost management systems using ABC (Oracle, Redwood, Calif). Detailed ABC assessed all direct, semidirect, and indirect costs, with special attention to robotic capital depreciation, maintenance, and supplies. Direct costs included all intraoperative and perioperative supplies, drugs, and blood products attributed to a specific patient encounter. Operating room time was the activity driver for all total costs incurred other than direct patient supplies, drugs, and blood. Semidirect costs included salaries, purchased services (repair costs, system maintenance, external vendor costs), and other supplies not included in direct costs. These were allocated via institutional cost drivers specific to surgical services and tracked to the patient encounter based on operating room time. Additional costs for revenue-generating units, such as ICUs, nursing step-down units, and diagnostic services, were allocated the relevant time-based patient-level proportion of total cost as unit operating costs. These groups included dietary, diagnostics, pharmacy, nursing, surgical services, and robotic capital depreciation amortized over a 5-year estimated useful life with $60 \%$ utilization. ${ }^{22,23}$ Indirect costs included physician services, administration, utilities, and facility management. All data were compiled and analyzed, and accuracy was confirmed by institutional fiscal services experts.

\section{Echocardiographic Data}

Echocardiography was performed on all RMVR patients before dismissal or within 30 days and at 1 year following the index operation with $100 \%$ follow-up. All patients in both the RMVR and SMVR groups were tracked for valve-related reoperation. Any mitral regurgitation (MR) greater than trace to mild following mitral repair was considered a failure.

\section{Statistical Methods}

Baseline demographic, clinical, and procedural characteristics were compared between the SMVR and RMVR groups. Continuous variables are summarized as median (range), and categorical variables are presented as number (percent). In recognition of the potential skewness of some variables, nonparametric tests (Wilcoxon-Mann-Whitney) were used to compare continuous variables between groups, and the $\chi^{2}$ test was used for categorical variables (Fisher exact test for variables with small cell sizes).

All preoperative variables from the institutional Society of Thoracic Surgeons (STS) cardiac surgery database were considered candidate 
variables for a multivariable logistic regression without exclusion to create propensity scores for receiving a RMVR versus a SMVR. The propensity scores were used to match patients who underwent RMVR to those who underwent SMVR on a set of demographic and clinical characteristics. The final multivariable logistic regression used to create propensity scores yielded a c-statistic of 0.81 and included the following variables: procedure (mitral repair vs replacement), sex, age, body mass index, elective versus urgent status, diabetes, preoperative dialysis, hypertension, infective endocarditis, cerebrovascular disease, chronic lung disease, home oxygen use, bronchodilator use, New York Heart Association class III or IV, presence of arrhythmia, and ejection fraction.

After calculation of propensity scores, patients undergoing RMVR were randomly sequenced and matched 1:1 without replacement to SMVR patients using a caliper distance of 0.10 to derive matched patient pairs. Between-group comparisons were repeated in the propensity-matched population to ensure adequate balance in the risk profile. Further adequacy of the matching procedure was corroborated by a comparison of the STS predicted risk of mortality (STS PROM) outcome measure, as well as the predicted risk of mortality and morbidity (STS PROMM). Outcomes were compared between the propensity-matched groups using standardized mean differences. All statistical analyses were performed using SAS version 9.4 (SAS Institute, Cary, NC).
The primary study endpoint was the assessment of total costs for patients undergoing each type of procedure (repair or replacement), ICU hours, and postoperative LOS in days. Patient-level cost accounting was examined by a review of patient-specific financial records from completion of surgery to discharge. The secondary endpoint was the incidence of mitral reoperation or existence of greater than mild MR during follow up.

This study received Institutional Review Board endorsement as a quality improvement initiative at the University of Pittsburgh (IRB \#PRO08050238) and West Virginia University (ID \#1704557818), and a waiver of consent was granted.

\section{RESULTS}

\section{Overall Population Demographics}

A total of 210 patients underwent SMVR and 118 patients underwent RMVR during the study period. Demographic data for the 2 groups are presented in Table 1.

Mitral valve repair was performed more often in the RMVR group than in the SMVR group (repair rate, $88.1 \%$ vs $69.0 \% ; P<.001)$. Compared with the SMVR group, the RMVR group was younger age (median, 61 years

TABLE 1. Preoperative characteristics of sternotomy versus robot-assisted mini-thoracotomy (all patients)

\begin{tabular}{|c|c|c|c|c|}
\hline Characteristic & Sternotomy & Robot-assisted & $P$ value & SMD \\
\hline Number of patients & 210 & 118 & & \\
\hline $\begin{array}{l}\text { Procedure } \\
\text { MV replacement, n (\%) } \\
\text { MV repair, n (\%) }\end{array}$ & $\begin{array}{r}65(31.0) \\
145(69.0)\end{array}$ & $\begin{array}{r}14(11.9) \\
104(88.1)\end{array}$ & $<.001$ & 0.118 \\
\hline Male sex, n (\%) & $96(45.7)$ & $71(60.2)$ & .012 & 0.044 \\
\hline Age, $y$, median (range) & $65.0(21.0-89.0)$ & $61.0(20.0-85.0)$ & .009 & 0.085 \\
\hline BMI, median (range) & $27.1(13.0-46.1)$ & $25.9(15.1-43.3)$ & .098 & 0.075 \\
\hline $\begin{array}{l}\text { Status, } \mathrm{n}(\%) \\
\text { Elective } \\
\text { Urgent } \\
\text { Diabetes }\end{array}$ & $\begin{array}{r}111(52.9) \\
99(47.1) \\
48(22.9)\end{array}$ & $\begin{array}{r}100(84.7) \\
18(15.3) \\
12(10.2)\end{array}$ & $<.001$ & 0.034 \\
\hline Dialysis & $8(3.8)$ & $2(1.7)$ & .285 & 0.067 \\
\hline Hypertension & $141(67.1)$ & $72(61.0)$ & .265 & 0.000 \\
\hline Infectious endocarditis & $31(14.8)$ & $8(6.8)$ & .032 & 0.114 \\
\hline Cerebrovascular disease & $37(17.6)$ & $10(8.5)$ & .023 & 0.148 \\
\hline Chronic lung disease (moderate-severe) & $20(9.5)$ & $5(4.2)$ & .083 & 0.089 \\
\hline Home oxygen & $8(3.8)$ & $4(3.4)$ & .846 & 0.057 \\
\hline Inhaled bronchodilator & $41(19.5)$ & $11(9.3)$ & .015 & 0.074 \\
\hline Peripheral vascular disease & $23(11.0)$ & $11(9.3)$ & .642 & 0.201 \\
\hline Previous pacemaker & $9(4.3)$ & $1(0.8)$ & .041 & 0.086 \\
\hline Previous AICD & $5(2.4)$ & $5(4.2)$ & .558 & 0.203 \\
\hline NYHA class III-IV & $116(55.2)$ & $34(28.8)$ & $<.001$ & 0.069 \\
\hline Preoperative arrhythmia (any) & $99(47.1)$ & $23(19.5)$ & .000 & 0.050 \\
\hline Preoperative ejection fraction & $58.0(15.0-76.0)$ & $60.0(5.0-75.0)$ & .001 & 0.077 \\
\hline STS PROM & $1.5(0.2-34.0)$ & $0.7(0.2-14.4)$ & $<.001$ & 0.178 \\
\hline STS PROMM & $17.3(5.2-89.2)$ & $10.5(4.8-59.5)$ & $<.001$ & 0.165 \\
\hline
\end{tabular}

$S M D$, Standard mean difference; $M V$, mitral valve; $B M I$, body mass index; $A I C D$, automated implantable cardioverter defibrillator; NYHA, New York Heart Association; STS, Society of Thoracic Surgeons; PROM, predicted risk of mortality; PROMM, predicted risk of major morbidity or mortality. 
vs 65 years; $P=.009)$ and had a higher rate of elective operation $(84.7 \%$ vs $52.9 \% ; P<.001)$, a lower rate of diabetes $(10.2 \%$ vs $22.9 \% ; P=.004)$, a lower rate of infective endocarditis $(6.8 \%$ vs $14.8 \% ; P<.032)$, a lower rate of cerebrovascular disease $(8.5 \%$ vs $17.6 \% ; P=.023)$, and a lower proportion of patients with New York Heart Association class III or IV heart failure $(28.8 \%$ vs $55.3 \%$; $P<.001)$. The STS PROM differed significantly between the SMVR and RMVR groups in the unmatched total population $(1.5 \%$ vs $0.7 \% ; P<.001)$, as did STS PROMM $(17.3 \%$ vs $10.5 \% ; P<.001)$.

\section{Propensity Matching}

The SMVR and RMVR groups were assigned propensity scores, resulting in 91 matched pairs (Table 2). After propensity matching, no significant preoperative differences were observed between the SMVR and RMVR groups.
Neither STS PROM nor STS PROMM differed significantly between the matched SMVR and RMVR groups $(0.8 \%$ vs $0.9 \% ; P=.431$ and $11.6 \%$ vs $11.3 \% ; P=.382$, respectively).

\section{Perioperative Variables in the Propensity-Matched Cohort}

All SMVR and RMVR surgeries were performed with none to trace MR documented by immediate postoperative transesophageal echocardiography. Perioperative outcome variables were compared between the propensity-matched SMVR and RMVR groups (Table 3). There were 2 operative deaths in the SMVR group and none in the RMVR group $(P=.172)$. Total perfusion time was greater in the RMVR group (162 minutes vs 124 minutes; $P<.001$ ). Patients in the RMVR group were more likely to be extubated in the operating room $(74.7 \%$ vs $18.7 \% ; P<.001)$, spent

TABLE 2. Preoperative characteristics of sternotomy versus robot-assisted mini-thoracotomy (propensity-matched cohort)

\begin{tabular}{|c|c|c|c|}
\hline Characteristic & Sternotomy & Robot-assisted & $P$ value \\
\hline Number of patients & 91 & 91 & \\
\hline $\begin{array}{l}\text { Procedure } \\
\text { MV replacement, n (\%) } \\
\text { MV repair, n (\%) }\end{array}$ & $\begin{array}{l}17(18.7) \\
74(81.3)\end{array}$ & $\begin{array}{l}13(14.3) \\
78(85.7)\end{array}$ & .424 \\
\hline Male sex, $n(\%)$ & $50(54.9)$ & $52(57.1)$ & .765 \\
\hline Age, $y$, median (range) & $62.0(21.0-86.0)$ & $62.0(20.0-85.0)$ & .543 \\
\hline BMI, median (range) & $25.8(13.0-42.5)$ & $25.9(15.1-43.3)$ & .777 \\
\hline $\begin{array}{l}\text { Status } \\
\quad \text { Elective, n (\%) } \\
\text { Urgent, n (\%) }\end{array}$ & $\begin{array}{l}71(78.0) \\
20(22.0)\end{array}$ & $\begin{array}{l}75 \text { (82.4) } \\
16(17.6)\end{array}$ & .505 \\
\hline Diabetes, n (\%) & $11(12.1)$ & $10(11.0)$ & .817 \\
\hline Dialysis, n (\%) & $3(3.3)$ & $2(2.2)$ & .650 \\
\hline Hypertension, $\mathrm{n}(\%)$ & $57(62.6)$ & $57(62.6)$ & 1.000 \\
\hline Infectious endocarditis, $\mathrm{n}(\%)$ & $10(11.0)$ & $7(7.7)$ & .445 \\
\hline Cerebrovascular disease, $\mathrm{n}(\%)$ & $11(12.1)$ & $7(7.7)$ & .321 \\
\hline Chronic lung disease (moderate-severe), n (\%) & $7(7.7)$ & $5(5.5)$ & .550 \\
\hline Home oxygen, $\mathrm{n}(\%)$ & $4(4.4)$ & $3(3.3)$ & .700 \\
\hline Inhaled bronchodilator, $\mathrm{n}(\%)$ & $10(11.0)$ & $8(8.8)$ & .620 \\
\hline Peripheral vascular disease, $\mathrm{n}(\%)$ & $5(5.5)$ & $10(11.0)$ & .178 \\
\hline Previous pacemaker, $\mathrm{n}(\%)$ & $2(2.2)$ & $1(1.1)$ & .394 \\
\hline Previous AICD, n (\%) & $1(1.1)$ & $4(4.4)$ & .296 \\
\hline NYHA class III-IV, n (\%) & $33(36.3)$ & $30(33.0)$ & .640 \\
\hline Preoperative arrhythmia (any), n (\%) & $25(27.5)$ & $23(25.3)$ & .737 \\
\hline Preoperative ejection fraction, median (range) & $58.0(30.0-75.0)$ & $60.0(5.0-75.0)$ & .064 \\
\hline STS PROM, median (range) & $0.8(0.2-33.6)$ & $0.9(0.2-14.4)$ & .431 \\
\hline STS PROMM, median (range) & $11.6(5.2-89.2)$ & $11.3(5.3-59.5)$ & .382 \\
\hline
\end{tabular}

$M V$, Mitral valve; $B M I$, body mass index; $A I C D$, automated implantable cardioverter defibrillator; NYHA, New York Heart Association; STS, Society of Thoracic Surgeons; PROM, predicted risk of mortality; PROMM, predicted risk of major morbidity or mortality. 
TABLE 3. Perioperative outcomes of sternotomy versus robot-assisted mini-thoracotomy (propensity-matched cohort)

\begin{tabular}{|c|c|c|c|}
\hline Outcome & Sternotomy & Robot-assisted & $P$ value \\
\hline Number of patients & 91 & 91 & \\
\hline Perfusion time, min, median (range) & $124(50-305)$ & $162(88-347)$ & $<.001$ \\
\hline Cross-clamp time, min, median (range) & $98(35-260)$ & $108(53-283)$ & .099 \\
\hline Extubation in operating room, $\mathrm{n}(\%)$ & $17(18.7)$ & $68(74.7)$ & $<.001$ \\
\hline Initial hours of ventilation, median (range) & $3.4(0.7-325)$ & $3.9(1.4-46.2)$ & .231 \\
\hline Reintubation, n (\%) & $3(3.3)$ & $5(5.5)$ & .469 \\
\hline Total postoperative ventilation hours, median (range) & $3.0(0.0-325)$ & $0.0(0.0-325)$ & $<.001$ \\
\hline Initial ICU hours, median (range) & $31.0(14.5-555)$ & $27.0(14.7-242)$ & .004 \\
\hline Readmission to ICU, n (\%) & $5(5.5)$ & $3(3.3)$ & .469 \\
\hline Total ICU hours, median (range) & $34.0(0.0-555)$ & $27.5(14.7-470)$ & .003 \\
\hline Any complications, $\mathrm{n}(\%)$ & $49(53.8)$ & $45(49.5)$ & .553 \\
\hline RTOR bleeding, $\mathrm{n}(\%)$ & $1(1.1)$ & $3(3.3)$ & .267 \\
\hline RTOR valve dysfunction, $\mathrm{n}(\%)$ & $1(1.1)$ & $0(0.0)$ & .279 \\
\hline Postoperative venous thromboembolism, n (\%) & $1(1.1)$ & $1(1.1)$ & .951 \\
\hline Postoperative pulmonary thromboembolism, n (\%) & $0(0.0)$ & $0(0.0)$ & NA \\
\hline Postoperative permanent stroke, $\mathrm{n}(\%)$ & $0(0.0)$ & $0(0.0)$ & NA \\
\hline Postoperative TIA, n (\%) & $1(1.1)$ & $1(1.1)$ & .951 \\
\hline Postoperative pneumonia, n (\%) & $0(0.0)$ & $1(1.1)$ & .294 \\
\hline Postoperative renal failure, $\mathrm{n}(\%)$ & $1(1.1)$ & $0(0.0)$ & .335 \\
\hline Postoperative dialysis required, $\mathrm{n}(\%)$ & $0(0.0)$ & $0(0.0)$ & NA \\
\hline Postoperative cardiac arrest, $\mathrm{n}(\%)$ & $2(2.2)$ & $0(0.0)$ & .170 \\
\hline Postoperative multisystem failure, $\mathrm{n}(\%)$ & $1(1.1)$ & $0(0.0)$ & .335 \\
\hline Postoperative atrial fibrillation, $\mathrm{n}(\%)$ & $35(38.5)$ & $33(36.3)$ & .836 \\
\hline Postoperative rhythm permanent device, $\mathrm{n}(\%)$ & $5(5.5)$ & $0(0.0)$ & .023 \\
\hline DSWI, n (\%) & $0(0.0)$ & $0(0.0)$ & NA \\
\hline Superficial infection, $\mathrm{n}(\%)$ & $0(0.0)$ & $0(0.0)$ & NA \\
\hline Postoperative sepsis, n (\%) & $0(0.0)$ & $1(1.1)$ & .294 \\
\hline Postoperative LOS, median (range) & $7(3-45)$ & $5(2-28)$ & $<.001$ \\
\hline Total LOS, median (range) & $7(4-51)$ & $5(2-33)$ & $<.001$ \\
\hline Readmission at $<30 \mathrm{~d}, \mathrm{n}(\%)$ & $14(15.4)$ & $8(8.8)$ & .172 \\
\hline Operative death, n (\%) & $2(2.2)$ & $0(0.0)$ & .172 \\
\hline
\end{tabular}

ICU, Intensive care unit; RTOR, return to operating room; NA, not applicable; TIA, transient ischemic attack; DSWI, deep sternal wound infection; LOS, length of stay.

less initial time in the ICU (median, 27 hours vs 31 hours; $P=.004)$, had less total ICU time (27.5 hours vs 34.0 hours; $P=.003)$, and had a shorter postoperative LOS (5 days vs 7 days; $P<.001)$. A trend toward lower readmission rates in the RMVR group versus SMVR was observed, although this did not achieve statistical significance $(8.8 \%$ vs $15.4 \% ; P=.172$ ).

\section{Financial Cost Analysis}

No significant differences were found in the total cost between the SMVR and RMVR technique on a per-patient basis (median, $\$ 28,241$ vs $\$ 27,662 ; P=.273$ ). However, multiple differences in direct, semidirect, and indirect per patient costs between SMVR and RMVR were observed
(Table 4). SMVR-related costs were higher than RMVRrelated costs in the areas of blood utilization ( $\$ 74$ vs $\$ 39$; $P=.014)$, salaries ( $\$ 7181$ vs $\$ 5655 ; P<.001)$, and unit supporting costs $(\$ 5811$ vs $\$ 4131 ; P<.001)$. RMVR-related costs were higher in the areas of total supplies (\$8782 vs $\$ 6219 ; P<.001)$, unit operating cost $(\$ 2523$ vs $\$ 2270$; $P=.005)$, and capital depreciation costs $(\$ 840$ vs $\$ 674$; $P<.001)$.

\section{Durability}

Echocardiographic data was obtained in all patients in the RMVR group. No patients in the RMVR group demonstrated greater than trace MR at 1-year follow-up. No patients in the RMVR group required reoperation secondary 
TABLE 4. Costs of full sternotomy versus robot-assisted mini-thoracotomy (propensity-matched cohort)

\begin{tabular}{lccc}
\hline \multicolumn{1}{c}{ Parameter } & Sternotomy & Robot-assisted & P value \\
\hline Number of patients & 91 & 91 & $8782(7438-9720)$ \\
Total supplies, median (range) & $6219(5006-9041)$ & $6099(5585-7597)$ & $<.001$ \\
$\quad$ Patient & $4153(3434-6806)$ & $2195(1527-2815)$ & $<.001$ \\
$\quad$ Unit & $1859(1409-2637)$ & $1056(864-1400)$ & .131 \\
Total drugs, median (range) & $1189(895-1945)$ & $940(733-1312)$ & $.139(79-186)$ \\
$\quad$ Patient & $1088(833-1852)$ & $2523(2187-3064)$ & .017 \\
$\quad$ Unit & $90(11-190)$ & $39(0-222)$ & .028 \\
Unit operating cost, median (range) & $2270(1787-2809)$ & $5655(4842-7431)$ & .005 \\
Blood, median (range) & $74(39-342)$ & $840(738-1030)$ & .014 \\
Salaries, median (range) & $7181(5655-10,474)$ & $4131(3570-5615)$ & $<.001$ \\
Depreciation, median (range) & $674(563-878)$ & $23,048(19,706-29,841)$ & .001 \\
Unit supporting cost, median (range) & $5811(4125-10,497)$ & $4088(3165-5146)$ & .001 \\
Total controllable cost, median (range) & $26,810(19,218-44,924)$ & $27,662(23,018-34,996)$ & .547 \\
\hline Indirect cost, median (range) & $4221(3094-5732)$ & .273 \\
\hline Total cost, median (range) & $28,241(23,227-40,466)$ &
\end{tabular}

All costs are in US dollars per patient.

to valve-related dysfunction, whereas 1 valve-related reoperation was required in the SMVR group $(P=.279)$.

\section{DISCUSSION}

This study examined propensity-matched patients undergoing conventional sternotomy and robotic mitral valve operations performed by experienced mitral surgeons to assess 1-year durability and cost following commencement of a robotic program. RMVR was found to be durable, with no patient exhibiting more than trace MR at 1-year followup. After accounting for robotic capital and instrumentation costs, no significant differences were observed between the robotic and sternotomy approaches, as assessed by patientspecific $\mathrm{ABC}$ accounting.

The overall mortality rate following isolated mitral operations in the United States is $2.9 \%$, with $14.5 \%$ of these

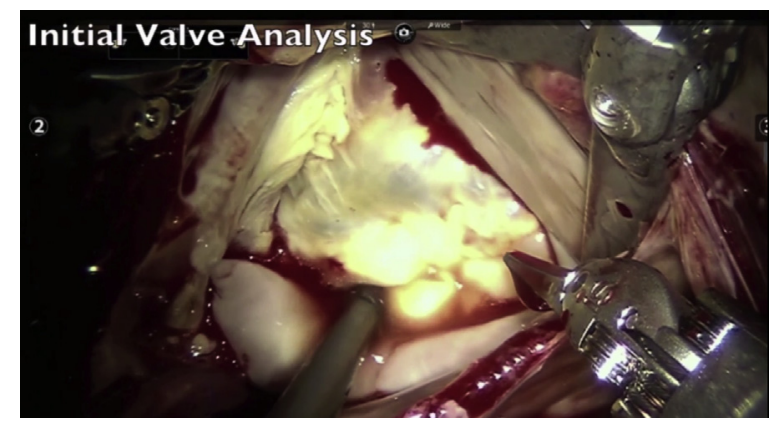

VIDEO 1. Dr Vinay Badhwar summarizes the study and explains its relevance while reviewing one of the robotic mitral valve repair cases performed during the study period. Video available at: https://www.jtcvs. org/article/S0022-5223(18)30938-3/fulltext. operations performed via minimally invasive or robotic techniques. $^{21}$ Currently, isolated mitral valve repairs, $11 \%$ of which are performed robotically, are associated with mortality of only $1.0 \%{ }^{21}$ However, despite the resurgence in interest on the part of patients and surgeons, questions persist as to the merits of robotic technology on the basis of quality and cost.

Robotic mitral operations are not easier than sternotomy operations, and gaining facility with telemanipulation technology involves a learning curve. ${ }^{4,12}$ Surgeons not otherwise experienced in mitral repair, including the nuances of echocardiogram interpretation and imaging-guided techniques, ${ }^{24}$ may find this learning curve steeper than those with ample open or minimally invasive repair experience. ${ }^{25}$ Concerns of quality must be respected, especially when dealing with a largely elective, low-risk population. Thus, surgeons unable to perform minimally invasive nonrobotic mitral repair with similar outcomes as obtained with sternotomy are advised to consider additional training before embarking on a complete switch to a robotic platform. ${ }^{25,26}$ In the present study, the 2 surgeons with $>10$ years of mitral repair experience and a minimum of 5 years of minimally invasive nonrobotic experience performed all RMVR operations. Cases for RMVR were not preselected based on pathoanatomic complexity or bileaflet disease, and the repair techniques used were those routinely applied for SMVR (Video 1). ${ }^{27}$ Echocardiography was performed before dismissal and 30 days and 1 year postsurgery in all patients, with follow-up performed by the operative surgeon in all cases. In this propensity-matched cohort, all patients had none to trace 
MR immediately following surgery, and only 1 patients in the SMVR group required mitral valve replacement for early postoperative repair failure. All patients in the RMVR group maintained none to trace MR through 1-year echocardiographic follow-up.

Assessments of costs in cardiac surgery have been estimated by relative value units, cost-to-charge ratios, or comparisons of hospital charges to regional historical national provider references. ${ }^{10-17}$ Although helpful to provide an approximation of the value of minimally invasive or robotic mitral surgery compared with sternotomy, many of these estimates reached either increased or cost-neutral conclusions without accounting for the cost of the robot itself. Because relative value units are preset based on the procedure, its use as the sole arbiter of cost does not accurately account for real-time variations in patient care. ${ }^{18,19}$ Estimates provided by hospital charges are prone to institutional variation, and these are often dependent on historical references on cost. Applying $\mathrm{ABC}$ strategies permits the assessment of more precise resource utilization at the level of the patient encounter inclusive of direct, semidirect, and indirect costs by $\mathrm{ABC}$ cost drivers. ${ }^{19,20,28}$ In the present study, costs were assigned to each episode of care for each patient and tabulated in real time with $\mathrm{ABC}$ drivers to account for direct, semidirect, and indirect costs, including those associated with use of the robot. Robot-associated costs encompassed the total cost of instruments used per case, as well as capital depreciation and maintenance costs. Because robot use is often shared among hospital surgical services, studies have assessed robot costs assuming $60 \%$ utilization over a 7 -year amortization period. ${ }^{23}$ In the current study, a more aggressive 5-year amortization period was used. Despite this tighter assignment of robotic cost, the overall patient costs were nearly identical in the RMVR and SMVR groups. Although, unexpectedly, capital and equipment costs were not much higher in the matched RMVR patients, reductions in ICU time gained with more frequent operating room extubation, ${ }^{29}$ as well as an overall lower LOS, led to significant cost savings. The use of $\mathrm{ABC}$ enabled a real-time and patient-level assessment of the true costs inclusive of operative time, equipment, and postoperative outcomes following RMVR and SMVR.

This study has several limitations. As a retrospective cohort study, an inherent selection bias may exist that cannot be fully eliminated. Although propensity matching is a reliable method to minimize bias, many factors, including operative clinical judgment on when to offer SMVR versus RMVR, might not be fully represented in institutional databases to account for intention to treat. Notwithstanding, no patient in the RMVR cohort underwent conversion to SMVR or from preoperatively planned repair to replacement. Despite the application of unified protocolized care pathways for extubation, ${ }^{29}$ transfusion, and ICU care for all patients regardless of approach, the potential for performance bias might not be fully accounted for. Because these elements have the potential to impact cost, it is recommended that protocolized care pathways be in place when initiating a robotic program. Longitudinal echocardiographic outcomes of mitral repair via sternotomy have been institutionally well established. Because this study was a quality initiative to study robotic program initiation, 1-year echocardiography was obtained to assess whether this method was consistent with established norms with sternotomy. We recognize that the absence of a temporal echocardiographic comparator of 1-year sternotomy repairs is a limitation; however, no patient in the robotic group had more that trace to mild MR at 1 year postsurgery. Although a randomized trial may add clarity, differences in team experience, intricacies of patient care and protocolized management, and inherent cost-efficiencies among institutions may make comparisons difficult. The RMVR cases were performed in an institution in which several surgical services used the robot, leading to shared staff experience and team learning, the benefits of which might not be fully accounted for in this analysis. Although precise costs related to patient-level resource consumption were assessed in this propensity-matched study, patient acuity, surgeon experience and utilization rates may vary among institutions, and thus the initial costs in less-experienced centers may be different.

The introduction of robotic technology must be met with a full understanding of its merits and weaknesses. ${ }^{30}$ This form of technological innovation may result in substantial increases in volume as patients seek out this therapy, but it may too be an important driver of cost growth. Robotic cardiac surgery is here to stay. Teams with experienced surgeons dedicated to continuous development and education have the best chance of growing successful programs while staying on the correct side of the cost curve. Successful teams focus on the maintenance of quality at all costs.

\section{CONCLUSIONS}

Experienced mitral valve repair surgeons may transition from a conventional to robotic approach without sacrificing cost, quality, or 1-year durability. An ABC approach may augment the accuracy of assessing healthcare expenditures in cardiac surgery.

\section{Conflict of Interest Statement}

Authors have nothing to disclose with regard to commercial support.

\section{References}

1. Murphy DA, Moss E, Binongo J, Miller JS, Macheers SK, Sarin EL, et al. The expanding role of endoscopic robotics in mitral valve surgery: 1,257 consecutive procedures. Ann Thorac Surg. 2015;100:1675-81; discussion 1681-2. 
2. Cao C, Wolfenden H, Liou K, Pathan F, Gupta S, Nienaber TA, et al. A metaanalysis of robotic vs. conventional mitral valve surgery. Ann Cardiothorac Surg. 2015;4:305-14.

3. Yoo JS, Kim JB, Jung SH, Kim DH, Choo SJ, Chung CH, et al. Mitral durability after robotic mitral valve repair: analysis of 200 consecutive mitral regurgitation repairs. J Thorac Cardiovasc Surg. 2014;148:2773-9.

4. Gillinov AM, Mihaljevic T, Javadikasqari H, Suri RM, Mick SL, Navia JL, et al. Early results of robotically assisted mitral valve surgery: analysis of the first 1,000 cases. J Thorac Cardiovasc Surg. 2018;155:82-91.e2.

5. Suri RM, Taggarse A, Burkhart HM, Daly RC, Mauermann W, Nishimura RA, et al. Robotic mitral valve repair for simple and complex degenerative disease: midterm clinical and echocardiographic quality outcomes. Circulation. 2015; 132:1961-8.

6. Cheng W, Fontana GP, De Robertis MA, Mirocha J, Czer LS, Kass RM, et al. Is robotic mitral valve repair a reproducible approach? J Thorac Cardiovasc Surg. 2010;139:628-33

7. Svensson LG, Atik FA, Cosgrove DM, Blackstone EH, Rajeswaran J, Krishnaswamy G, et al. Minimally invasive versus conventional mitral valve surgery: a propensity-matched comparison. J Thorac Cardiovasc Surg. 2010;139: 926-32. e1-2.

8. Folliguet T, Vanhuyse F, Constantino X, Realli M, Laborde F. Mitral valve repair robotic versus sternotomy. Eur J Cardiothorac Surg. 2006;29:362-6.

9. Woo YJ, Nacke EA. Robotic minimally invasive mitral valve reconstruction yields less blood product transfusion and shorter length of stay. Surgery. 2006; 140:263-7.

10. Moss E, Halkos ME. Cost effectiveness of robotic mitral valve surgery. Ann Cardiothorac Surg. 2017;6:33-7.

11. Hassan M, Miao Y, Lincoln J, Ricci M. Cost-benefit analysis of robotic versus nonrobotic minimally invasive mitral valve surgery. Innovations (Phila). 2015; 10:90-5

12. Charland PJ, Robbins T, Rodriguez E, Nifong WL, Chitwood RW Jr. Learning curve analysis of mitral valve repair using telemanipulative technology. J Thorac Cardiovasc Surg. 2011;142:404-10.

13. Kam JK, Cooray SD, Kam JK, Smith JA, Almeida AA. A cost-analysis study of robotic versus conventional mitral valve repair. Heart Lung Circ. 2010;19:413-8.

14. Canale LS, Colafranceschi AS. Is robotic mitral valve surgery more expensive than its conventional counterpart? Interact Cardiovasc Thorac Surg. 2015;20: 844-7.

15. Mihaljevic T, Koprivanac M, Kelava M, Goodman A, Jarrett C, Williams SJ, et al. Value of robotically assisted surgery for mitral valve disease. JAMA Surg. 2014; 149:679-86.

16. Downs EA, Johnston LE, LaPar DJ, Ghanta RK, Kron IL, Speir AM, et al. Minimally invasive mitral valve surgery provides excellent outcomes without increased cost: a multi-institutional analysis. Ann Thorac Surg. 2016;102:14-21.
17. Atluri P, Stetson RL, Hung G, Gaffey AC, Szeto WY, Acker MA, et al. Minimally invasive mitral valve surgery is associated with equivalent cost and shorter hospital stay when compared with traditional sternotomy. J Thorac Cardiovasc Surg. 2016;151:385-8.

18. Cooper R, Kramer TR. RBRVS costing: the inaccurate wolf in expensive sheep's clothing. J Health Care Finance. 2008;34:6-18.

19. West TD, Balas EA, West DA, Contrasting RCC. RVU, and ABC for managed care decisions: a case study compares three widely used costing methods and finds one superior. Healthc Financ Manage. 1996;50:54-61.

20. Ridderstolpe L, Johansson A, Skau T, Rutberg H, Ahlfeldt H. Clinical process analysis and activity-based costing at a heart center. J Med Syst. 2002 26:309-22.

21. Badhwar V, Rankin JS, He X, Jacobs JP, Gammie JS, Furnary AP, et al. The Society of Thoracic Surgeons mitral repair/replacement composite score: a report of the Society of Thoracic Surgeons quality measurement task force. Ann Thorac Surg. 2016;101:2265-71.

22. Leitao MM Jr, Bartashinik A, Wagner I, Lee SJ, Caroline A, Hoskins WJ, et al Cost-effectiveness analysis of robotic-assisted laparoscopy for newly diagnosed uterine cancers. Obstet Gynecol. 2014;123:1031-7.

23. Bijlani A, Hebert AE, Davitian M, May H, Speers M, Leung R, et al. A multidimensional analysis of prostate surgery costs in the United States: robotic-assisted versus retropubic radical prostatectomy. Value Health. 2016;19:391-403.

24. Badhwar V, Smith AJ, Cavalcante JL. A pathoanatomic approach to the management of mitral regurgitation. Trends Cardiovasc Med. 2016;26:126-34.

25. Rodriguez E, Nifong LW, Bonatti J, Casula R, Falk V, Folliguet TA, et al Pathway for surgeons and programs to establish and maintain a successfu robot-assisted adult cardiac surgery program. J Thorac Cardiovasc Surg. 2016 152:9-13.

26. Valdis M, Chu MW, Schlachta C, Kiaii B. Evaluation of robotic cardiac surgery simulation training: a randomized controlled trial. J Thorac Cardiovasc Surg. 2016;151:1498-505.e2.

27. Murashita T, Raffa GM, Wei L, Badhwar V. Robotic mitral repair with sliding leaflet valvuloplasty and remodeling partial annuloplasty. Multimed Man Cardiothorac Surg. 2016;2016.

28. Najjar PA, Strickland M, Kaplan RS. Time-driven activity-based costing for surgical episodes. JAMA Surg. 2017;152:96-7.

29. Badhwar V, Esper S, Brooks M, Mulukutla S, Hardison R, Mallios D, et al. Extubating in the operating room after adult cardiac surgery safely improves outcomes and lowers costs. J Thorac Cardiovasc Surg. 2014;148:3101-9.e1.

30. Barbash GI, Glied SA. New technology and health care costs: the case of robotassisted surgery. $N$ Engl J Med. 2010;363:701-4.

Key Words: mitral valve repair, robotic, cost 